\title{
Проблемы российского теплоснабжения и пути их решения 1
}

В.А. СТЕНнИКОВ, доктор технических наук, директор Института систем энергетики им. Л. А. Мелентьева CO PAH. E-mail: SVA@isem.irk.ru

А.В. ПЕНЬКОВСкИЙ, кандидат технических наук, Институт систем энергетики им. Л.А. Мелентьева СО РАН, Иркутск. E-mail: penkoffsky@isem.irk.ru

Аннотация. Теплоснабжение России, большая часть которой расположена на территории с суровым климатом, является важнейшей социальной отраслью экономики, во многом определяющей энергетическую безопасность страны. За прошедший период реформирования в теплоснабжении, как и в технологически, организационно и экономически связанной с ним электроэнергетической отрасли, накопилось множество проблем. Это обусловлено, прежде всего, отсутствием действенных механизмов управления их функционированием и развитием. При этом есть все основания полагать, что принятая Правительством РФ целевая модель теплового рынка не только не устраняет эти проблемы, но еще более обостряет ситуацию. На взгляд авторов, для изменения сложившейся ситуации необходимо провести ряд организационных преобразований на рынках электрической и тепловой энергии, направленных в первую очередь на трансформацию взаимоотношений поставщиков и потребителей энергии, а также включение в систему тарифообразования маркетинговых принципов. Ключевые слова: теплоснабжение; целевая модель рынка тепла; альтернативная котельная; реформирование; направления развития; интегрированные рынки энергии

\section{Современная ситуация в теплоснабжении}

Советский союз когда-то обладал одной из мощнейших энергетических систем в мире. Энергетическое хозяйство создавалось как единый комплекс, служащий основой для формирования и функционирования производительных сил, а одним из важнейших ее элементов являлись системы централизованного энергоснабжения на базе теплофикации (когенерации), позволяющие экономить до 40\% первичного топлива. История развития теплофикации в России насчитывает более 100 лет [Гуторов, Байбаков, 2003], но начало становления массовой городской теплофикации приходится на 1930-е гг., когда появились ТЭЦ малой и средней мощности (150-300 Гкал/ч), позволявшие передавать тепловую

\footnotetext{
${ }^{1}$ Исследование выполнено в рамках проекта III.17.4.4 № рег. АААА-А17-117030310437-4 программы фундаментальных исследований СО РАН.
} 
энергию потребителям, по современным меркам, на скромные расстояния в пределах 1,5-3 км. Расцвет же централизованного теплоэнергоснабжения пришелся на 1960-е гг., когда сооружались крупные ТЭЦ мощностью 1700-2300 Гкал/ч, обеспечивающие тепловой энергией потребителей уже в радиусе 10-12 км и более (Алма-Ата - 80 км, Свердловск - 40 км).

На закате СССР (конец 1980-х гг.) централизованное теплоснабжение в стране осуществлялось более чем от 900 ТЭЦ с суммарной тепловой мощностью около 200 тыс. Гкал/ч [Попырин и др., 1989]. По некоторым оценкам [Хрилев, 1988; Гашо и др., 2015], к 1989 г., по сравнению с 1940 г., суммарное производство тепловой энергии в системах централизованного теплоснабжения увеличилось в 65 раз и превысило по объему 1300 млн Гкал (рис. 1).

При этом развитие теплоснабжения осуществлялось за счет централизованного бюджетного финансирования, энергетические тарифы не соответствовали реальным затратам и в большей мере носили учетную функцию.

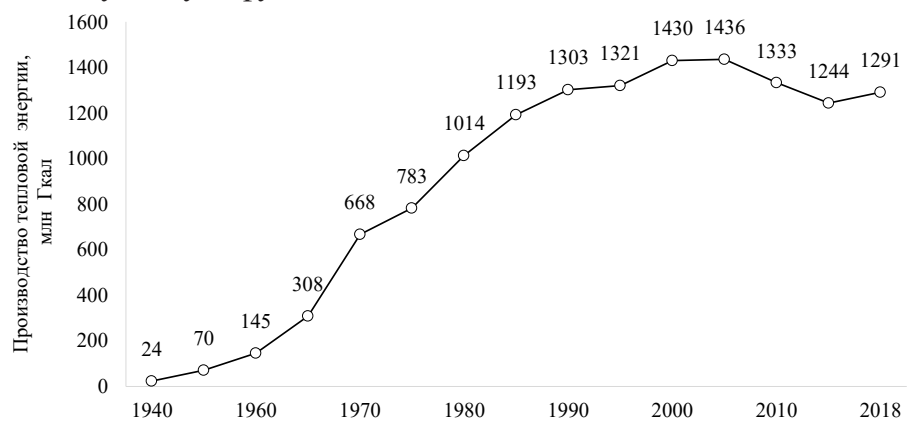

Puc. 1. Динамика производства тепловой энергии в централизованных системах СССР в 1940-2018 гг., млн Гкал

Процессы либерализации в теплоэнергетике, начатые в 1990-х гг. после развала СССР, привели к формированию новых экономических отношений между производителями, поставщиками и потребителями энергии, изменению форм собственности и переходу к самоокупаемости оказываемых услуг. В результате преобразований бизнес получил в наследство от СССР огромные фонды и, что очень важно, рынок подготовленных потребителей, однако он оказался не готовым 
работать в рыночных условиях. Несмотря на кардинальные организационно-технологические изменения, которые должны были способствовать эволюционированию отрасли, в теплоснабжении по-прежнему поддерживается административная схема управления, сохраняется диктат поставщиков над потребителями, надежность теплоснабжения падает, а тарифы растут без повышения качества предоставления услуг.

Все это приводит к уходу потребителей из централизованных систем на снабжение от собственных теплоисточников (процесс «котельнизации»), в результате чего теплоэнергетика постепенно теряет все достигнутые за советский период преимущества. За 1990-2010-ее гг. в России не было построено ни одной теплоэлектроцентрали (только в 2010 г. началось развитие нескольких действующих ТЭЦ за счет механизма ДПМ²), значительно сжался рынок потребителей.

При этом нарушилась отлаженная экономика ТЭЦ из-за сокращения отпуска тепловой энергии более чем в два раза и выработки электроэнергии - на 15\% [Некрасов и др., 2012] (табл. 1). Выработка электроэнергии по экономичному теплофикационному циклу сократилась, а по затратному для ТЭЦ конденсационному циклу - возросла. В результате экономия топлива от когенерации снизилась практически на $30 \%$.

\section{Таблица 1. Показатели эффективности теплофикации в России в 1991-2010 rr.}

\begin{tabular}{|l|c|c|c|}
\hline \multicolumn{1}{|c|}{ Показатель } & $\mathbf{1 9 9 1}$ & $\mathbf{2 0 0 0}$ & $\mathbf{2 0 1 0}$ \\
\hline Производство электроэнергии на ТЭЦ, млрд кВт & 418 & 275 & 355 \\
\hline В том числе по теплофикационному циклу, млрд кВт & 246 & 157 & 180 \\
\hline Отпуск тепла от ТЭЦ, млн Гкал & 792 & 409 & 394 \\
\hline В том числе из отборов турбин ТЭЦ, млн Гкал & 655 & 366 & 343 \\
\hline
\end{tabular}

Источник: [Некрасов и др., 2012].

Указанный период характеризовался преобладающим развитием децентрализованных автономных источников тепла с использованием главным образом импортного оборудования (рис. 2). Как показывают графики на рисунке, количество котельных росло более быстрыми темпами, чем их суммарная мощность, поскольку вводились в основном мелкие малоэффективные котельные.

2 ДПМ - Договор на предоставление мощности - механизм гарантии возврата инвестиционных затрат за счет специальной надбавки к тарифу. 
Средняя установленная мощность котельных за период с 2005 г. по 2018 г. уменьшилась на 23\% (с 9,6 до 7, 8 Гкал/ч).

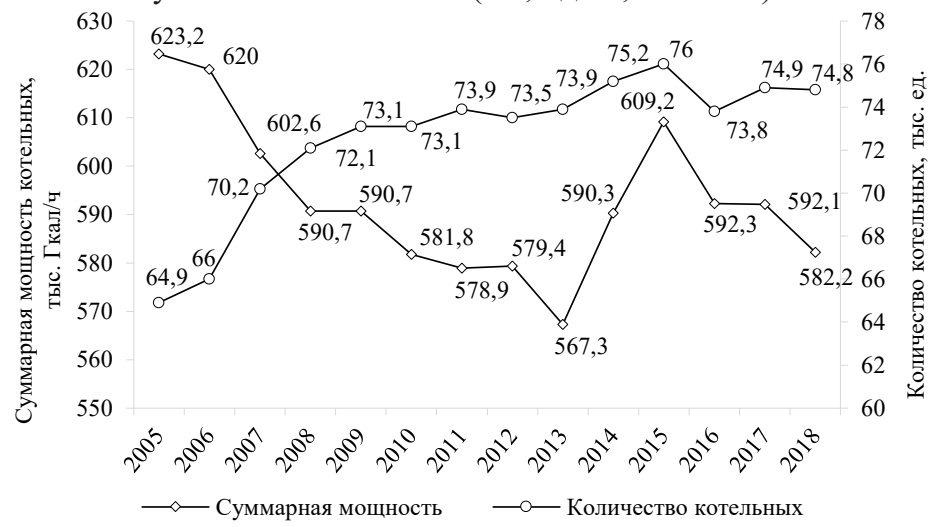

Источник: данные Росстата ${ }^{3}$.

Puc. 2. Динамика количества (правая шкала) и суммарной мощности котельных (левая шкала) в России в 2005-2018 гг., тыс. Гкал/ч

На фоне существенного ухудшения эффективности выработки тепла на ТЭЦ в течение всего периода реформ нарастали потери при транспортировке теплоэнергии потребителям. За 1995-2018 г. потери увеличились в 2,5 раза и составили 12,4\% от суммарного отпуска ${ }^{2}$.

Это еще более ухудшило экономику централизованного теплоснабжения на базе теплофикации, что закономерно отразилось на тарифах. Получился замкнутый круг: из-за роста тарифов крупные экономически устойчивые производственные потребители ускорили переход на собственные источники теплоснабжения (как правило, котельные). ТЭЦ в условиях сокращения сбыта вынуждены были еще больше повышать тарифы для оставшихся потребителей ${ }^{4}$.

В настоящее время теплоснабжение потребителей в России осуществляют около 21 тыс. предприятий. Действующие 522 тепловые электростанции (данные Росстата за 2017 г.)

\footnotetext{
${ }^{3}$ URL: http://www.gks.ru/free_doc/new_site/population/jil-f/jkh3.docx (дата обращения: 08.07.2019).

${ }^{4}$ Подробнее об ущербе, который нанесла котельнизация отрасли, см. [Богданов и др., 2008].
} 
вырабатывают всего 480 млн Гкал тепловой энергии в год (в 1991 г. - около 790 млн Гкал, в 1995 г. - 562 млн Гкал). Общая протяженность тепловых сетей в системах централизованного теплоснабжения по трассе уменьшилась до 170 тыс. км (было 177 тыс. км). Это свидетельствует о продолжающемся сокращении сектора централизованного теплоснабжения.

Одной из все более усугубляющихся проблем в теплоэнергетике является значительный износ основного оборудования, достигающий $60 \%$ и более (причем, это характерно как для большой, так и для малой теплоэнергетики). Несмотря на то, что амортизационные отчисления включены в тариф, их катастрофически не хватает из-за накопленного за предшествующие 20 лет износа. Процесс обновления основных фондов идет слишком медленно. В частности, темпы перекладки тепловых сетей в России не превышают $1 \%$ в год, тогда как оптимальный показатель должен составлять минимум $10 \%$ [Сергеев, 2018].

Другая проблема связана с высокой задолженностью потребителей за теплоснабжение. Она объясняется не только невысоким уровнем платежной дисциплины, но и неспособностью населения из-за низких доходов оплачивать высокие тарифы на тепло. По данным Росстата, общая сумма дебиторской задолженности организаций, оказывающих услуги теплоснабжения, на 1 января 2017 г. составила 475,7 млрд руб., ${ }^{5}$ из которых 57,2\% (271,7 млрд руб.) приходится на население. Одна из причин падение реальных доходов россиян, которое в период с 2013 по 2017 гг. составило более $11 \%{ }^{6}$. Другая - существенный рост тарифов, который по темпам значительно опережает инфляцию (рис. 3).

При официальной инфляции с 2008 по 2018 гг. 72,8\% в Казани тариф на тепловую энергию вырос в 5,5 раза, в Иркутске в 3,2 раза. Но, как ни парадоксально, по большому счету это не привело ни к притоку инвестиций, ни к активизации работ по модернизации, техническому перевооружению и развитию теплоснабжающих систем.

${ }^{5}$ URL: https://minenergo.gov.ru/view-pdf/10850/80685 (дата обращения: 08.07.2019).

${ }^{6}$ URL: http://ac.gov.ru/files/publication/a/16270.pdf (дата обращения: 08.07.2019). 


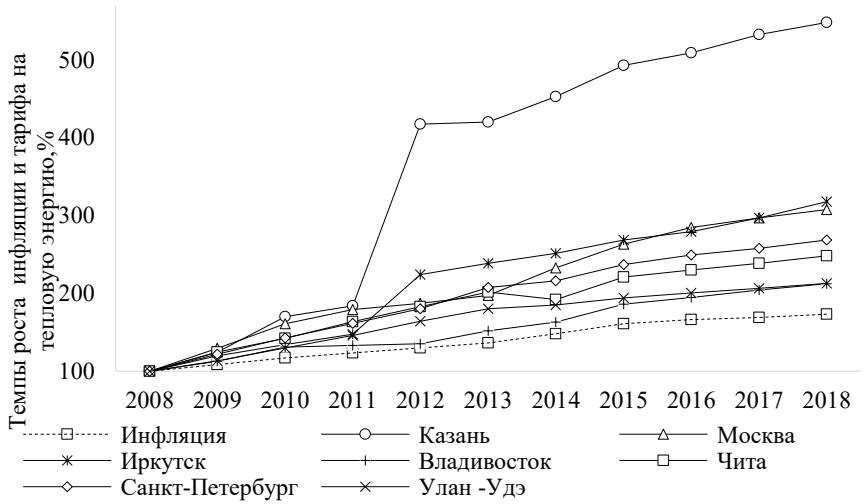

Источник: данные комитета по тарифам Республики Татарстан. URL: http:// kt.tatarstan.ru/rus/arhiv-tarifov-goskomiteta.htm; данные ПАО «Иркутскэнерго». URL: https://sbyt.irkutskenergo.ru/qa/3096.html; данные Росстата. URL: http://www. gks.ru/dbscripts/cbsd/DBInet.cgi?pl=1921001; данные департамента по тарифам Новосибирской области. URL: https://tarif.nso.ru/page/76; данные службы по тарифам Республики Бурятии. URL: http://egov-buryatia.ru/rst/activities/monitoring/ tariffs.php; данные сайта «Управление многоквартирным домом». URL: http:// youhouse.ru/tarify_zhkh/; данные ПАО «МОЭК». URL: https://www.moek.ru/about/ moek-shareinfo/tarify/;данныеTГK-14. URL: https://www.tgk-14.com/clients/zab/rst. php; данные департаментапо тарифам Приморского края. URL: https://primorsky. ru/authorities/executive-agencies/departments/tariffs/docs/statutes/2011/;данные сайта «Уровень инфляции в Российской Федерации». URL: http://уровень-инфляции.рф/\%D1\%82\%D0\%B0\%D0\%B1\%D0\%BB\%D0\%B8\%D1\%86\%D0\%B0_\%D 0\%B8\%D0\%BD\%D1\%84\%D0\%BB\%D1\%8F\%D1\%86\%D0\%B8\%D0\%B8.aspx (дата обращения: 08.07.2019).

Puc. 3. Динамика изменения тарифа на тепловую энергию по городам РФ в 2008-2018 гг.,\%

\section{Организационные структуры рынков тепловой энергии}

Все более обостряется проблема рассогласованности (разделения) рынков тепловой и электрической энергии, которые имеют тесную организационную и экономическую связь через ТЭЦ, работающие на обоих рынках. Технологически ТЭЦ, производя тепловую и электрическую энергию в комбинированном режиме, объединяет теплоснабжающую и электроэнергетическую системы. Теплофикационная генерация, обеспечивающая 46\% производства тепловой и 39\% электрической энергии в Россий,

\footnotetext{
${ }^{7}$ URL: http:/ac.gov.ru/files/publication/a/16709.pdf (дата обращения: 08.07.2019).
} 
исторически создавалась и продолжает успешно функционировать для энергоснабжения одних и тех же предприятий и территорий.

Более того, объем производства электроэнергии во многом зависит от выработки тепла, точно так же, как выручка ТЭЦ складывается из суммарной выручки от продажи электроэнергии и тепла. Вместе с тем ни ФЗ «Об электроэнергетике»", ни «О теплоснабжении» ${ }^{9}$ не затрагивают вопросы согласования и совместной работы этих рынков.

Технологическая структура обоих рынков и их интегрирующее начало показаны на рисунке 4. Каждый из них имеет свои правила организации энергоснабжения потребителей, свои регламенты регулирования, свои принципы тарифообразования и т.д. Так, рынок электроэнергии является конкурентным, а рынок тепловой энергии - регулируемой естественной монополией.

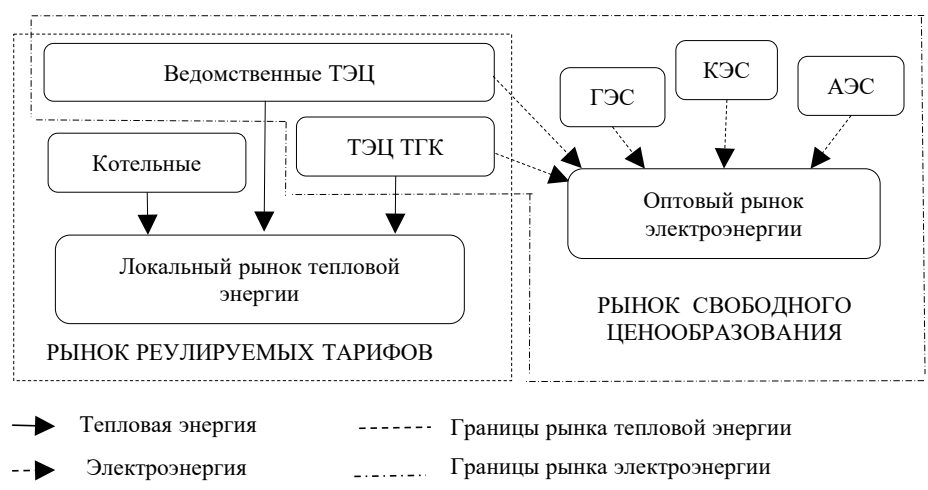

Puc. 4. Интегрированный рынок тепловой и электрической энергии

Вышеизложенные факторы обусловливают низкую конкурентоспособность ТЭЦ как на тепловом, так и на электроэнергетическом рынках и приводят к постепенной их деградации.

В первой редакции Ф3 «О теплоснабжении», принятого в 2010 г., была предложена модель теплоснабжения, аналогичная той, что успешно работает в скандинавских странах, Германии, Англии, Австрии, Швеции, ее структура приведена на рисунке 5.

\footnotetext{
${ }^{8}$ Федеральный закон «Об электроэнергетике» от 26. 03.2003 г. № 35-Ф3.

${ }^{9}$ Федеральный закон «О теплоснабжении» от от 27.07.2010 № 190-Ф3.
} 


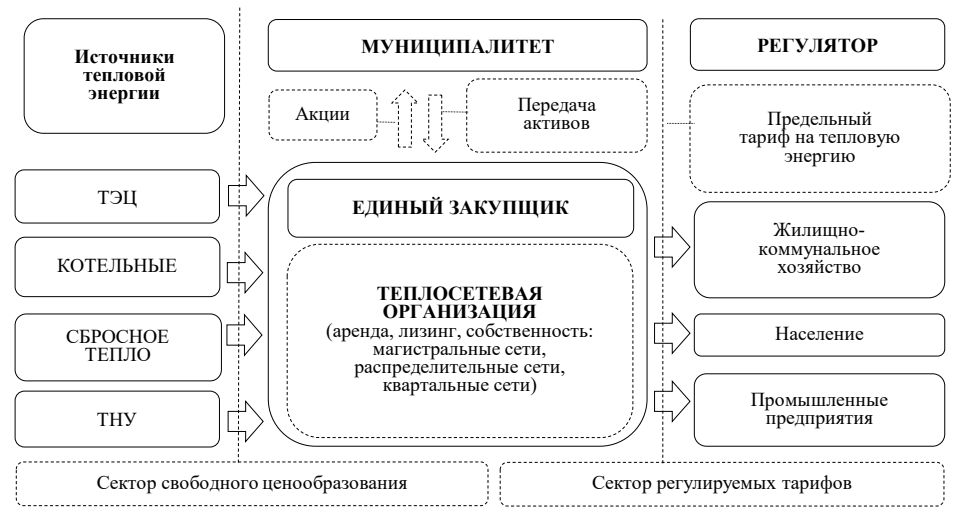

Puc. 5. Организационная модель конкурентного рынка теплоэнергии «Единый закупщик»

В рамках данной модели создается Единая теплоснабжающая организация (ЕТО), формируемая в виде «Единого закупщика», которая занимается естественно-монопольным видом деятельности по транспортировке и передаче тепловой энергии по тепловым сетям. Производство тепла на теплоисточниках относится к конкурентной сфере деятельности. Таким образом, выделяются сектор свободного ценообразования, на котором теплоэнергия приобретается у независимых теплоисточников (ТЭЦ, котельные, сбросовое тепло промышленных предприятий, теплонасосные установки) и регулируемый сектор, на котором теплоэнергия поставляется конечным потребителям под контролем общественного или государственного регулятора. Данная модель в полном объеме так и не была реализована.

В принятых в 2018 г. изменениях к федеральному закону «О теплоснабжении» ${ }^{10}$ и предложенной Правительством РФ Дорожной карте «Внедрение целевой модели рынка тепловой энергии» $^{11}$ была учреждена другая модель, пролоббированная крупными теплогенерирующими компаниями и предполагающая

${ }^{10}$ Федеральный закон от 27 июля 2010 г. № 190-Ф3 «О теплоснабжении» (ред. от 19.07.2018).

${ }^{11}$ Распоряжение Правительства Российской Федерации от 2 октября 2014 г. № 1949-р, План мероприятий («Дорожная карта») «Внедрение целевой модели рынка тепловой энергии». 
переход к ЕТО, создаваемой на базе крупных источников и тепловых сетей. Она фактически предполагает формирование единой монопольной структуры ЕТО, как показано на рисунке 6, которая также применяется в ряде стран. Однако отличием предлагаемой модели от ее зарубежного аналога являются отмена регулирования и введение либеральных цен на теплоэнергию, определяемых по ее величине на «альтернативной котельной» (АК). В отличие от скандинавских стран, где присутствует регулятор, в российской модели рынка тепловой энергии присутствует лишь контролирующий орган, функционал которого, по определению, не предполагает влияния на взаимоотношения участников и ограничивается только надзором за соблюдением регламентов реализуемой модели.

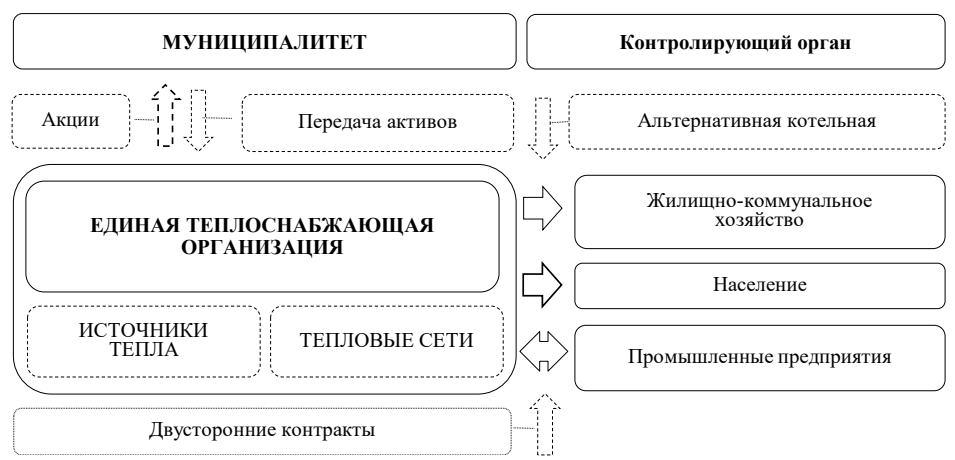

Puc. 6. Организационная модель рынка теплоэнергии «AK+ETO»

Согласование рынков электроэнергии и тепла в новых законодательных документах не предусматривается. Более того, о его необходимости даже не упоминается. Предложенная модель теплового рынка Единая теплоснабжающая организация плюс альтернативная котельная $(\mathrm{ETO}+\mathrm{AK})$ не решает и не может решить эту задачу.

Основополагающий принцип системы тарифообразования по уровню цены «альтернативной котельной» предполагает установление теплового тарифа на уровне расчетной стоимости теплоэнергии, произведенной на так называемой «альтернативной котельной», под которой понимается виртуальный (возможный) вновь создаваемый локальный источник тепла небольшой мощности (10 Гкал/ч), которым потребитель как бы может заменить 
централизованное теплоснабжение. Для определения параметров такой котельной берется предпосылка о применении наиболее современных и экономичных технологий, а также максимально эффективное использование ее установленной мощности. В процессе моделирования на основе ряда входных параметров (технологических и экономических), в соответствии с приемлемым для инвестора сроком окупаемости (не более 10 лет), исходя из суммарных дисконтированных затрат на строительство и эксплуатацию «альтернативной котельной», рассчитывается цена теплоэнергии, которая могла бы быть произведена этим источником. Если действующий тариф на тепловую энергию окажется ниже цены «альтернативной котельной», тогда разрабатывается, а затем реализуется график поэтапного (в течение пяти лет) повышения его уровня до этой цены АК в соответствии с утвержденными на федеральном уровне правилами индексации. Если действующий тариф выше цены «альтернативной котельной», его замораживают и затем в результате модернизации снижают до уровня цены АК.

Разработчики новой модели считают, что повышение тарифа до уровня цены альтернативной котельной будет способствовать привлечению инвестиций на развитие теплоснабжения. Однако стоит напомнить, что за прошедший период тарифы росли значительно быстрее инфляции, но это не способствовало инвестиционному притоку и проведению модернизации и техническому перевооружению систем.

Все регламентированные в новых правовых актах положения посвящены порядку реализации модели «АК+ЕТО» (рис. 6) и не затрагивают стратегических ориентиров реформирования теплоснабжения, направленных на преодоление сложившихся негативных тенденций [Гашо, 2013; Стенников, Славин, 2014; Макаров и др., 2018].

\section{Основные положения целевой модели рынка тепловой энергии}

Реализованная в федеральном законе концепция формирования новой модели теплоснабжения включает следующие основные принципы.

1. Отказ от государственного регулирования тарифов на тепловую энергию. 
2. Поэтапное доведение тарифа на тепловую энергию до уровня ее стоимости на «альтернативной котельной» (по сути, рост тарифа в 1,5-2 раза, без учета инфляции).

3. Формирование на базе крупных теплогенерирующих (как правило, ТГК) единых теплоснабжающих организаций.

4. Предоставление монополии ЕТО беспрецедентных полномочий, таких как установление предельных цен, заключение договоров по устанавливаемым в одностороннем порядке правилам и ценам, распределение нагрузок между теплоисточниками, разработка схемы теплоснабжения и т.д.

Эти положения ФЗ № 190 «О теплоснабжении» входят в противоречие со всеми канонами экономической теории, поскольку, по сути, закрепляют создание нерегулируемой монополии и узаконивают повышение тарифов до предельного уровня. При этом они не имеют никакого отношения к решению системных проблем отрасли - ни к совершенствованию теплоснабжения как такового (в части упорядочивания организационного управления, повышения эффективности, стимулирования сокращения издержек), ни к согласованию рынков тепловой и электрической энергии. Более того, они противоречат технической политике России по развитию теплофикации (когенерации), поскольку повышение тарифов до предельного уровня приведет к неизбежному снижению ее конкурентоспособности относительно вновь сооружаемых котельных, дальнейшему росту затрат и постепенной деградации.

Мы сравнили уровни цен на тепловую энергию во всех известных в настоящее время моделях ценообразования (свободное ценообразование в условиях конкурентного взаимодействия производителей; свободное ценообразование в условиях монопольного рынка; регулирование естественной монополии методами «затраты плюс»- на уровне средних суммарных затрат, маржинальных затрат, «альтернативная котельная»). Цена по «альтернативной котельной» оказалась наиболее высокой [Пеньковский, 2017].

Это обусловлено несколькими факторами: альтернативная котельная - это децентрализованный теплоисточник, и для него не действует эффект масштаба, работающий на снижение затрат; в цену включена инвестиционная составляющая, которая не должна учитываться для уже существующих систем; раздельный способ производства тепла в котельной и электроэнергии 
на конденсационной тепловой электростанции объективно менее эффективен по сравнению с комбинированным способом их производства, что также значительно повышает затраты.

На наш взгляд, введение тарифа, определяемого ценой «альтернативной котельной», фактически представляет собой возврат к действовавшему до 1996 г. физическому методу тарифообразования $^{12}$ в его худшем варианте из-за наличия в цене инвестиционной составляющей. Тарифообразование на базе физического метода основано на расчете затрат, при котором вся экономия от комбинированного производства энергии переносится на электроэнергию, что позволяет значительно уменьшить стоимость электроэнергии за счет существенного повышения стоимости сопутствующей (бросовой) тепловой энергии. Этот метод в свое время из-за высоких тарифов на тепло привел к массовому уходу потребителей на собственные теплоисточники («котельнизации»), при этом приток инвестиций в отрасль не увеличился.

Начиная с 1996 г, с целью спасения ТЭЦ от потери тепловой нагрузки, был введен пропорциональный метод разделения топлива, который привел к увеличению расходов топлива на электроэнергию и уменьшению на тепло (рис. 7).

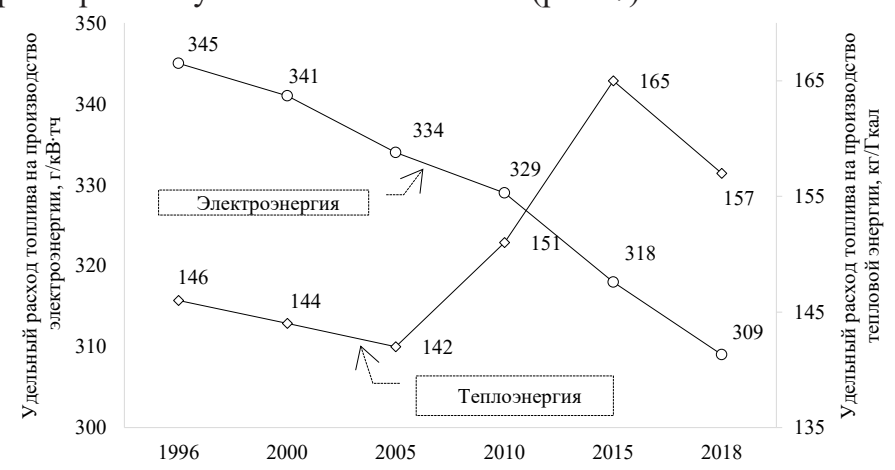

Puc. 7. Удельные расходы топлива на производство тепловой (правая шкала) и электрической (левая шкала) энергии на ТЭЦ в 1996-2018 гг.

\footnotetext{
${ }^{12}$ В основу физического метода положено распределение затрат пропорционально количеству топлива, израсходованного на каждый вид энергии на основе теплового баланса. При этом полагается, что на получение тепловой энергии из отборов турбин затрачивается такое же количество топлива, как и при отпуске теплоты непосредственно из котлов.
} 
Этот метод, и ныне действующий, тоже несовершенен. Объективности ради следует отметить, что до сих пор не существует научно обоснованного метода назначения (разделения) цен на электрическую и тепловую энергию, производимые на ТЭЦ, - ни для регулируемого, ни для либерализованного рынков [Стенников, Жарков, 2017].

Но переход на тарифы, определяемые по уровню «альтернативной котельной», может лишь способствовать очередному этапу «котельнизации» страны, когда наиболее платежеспособные потребители из-за высоких тарифов продолжат строительство собственных теплоисточников, экономичная выработка электроэнергии по эффективному теплофикационному циклу сократится, конкурентоспособность ТЭЦ и на тепловом, и на электроэнергетическом рынке упадет, а надежность и качество теплоснабжения снизятся [Стенников, Пеньковский, 2019].

На наш взгляд, предложенная модель теплового рынка «ЕТО+АК» требует пересмотра в следующих направлениях: ЕТО должна создаваться на базе естественно-монопольной сферы деятельности, т.е. передачи и распределения тепловой энергии; тариф, формируемый по цене «альтернативной котельной», может приниматься лишь в качестве предельного индикатора, выше которого действующий тариф не может подниматься, реально он должен быть ниже для обеспечения конкурентоспособности систем; достижение индикативного уровня должно сигнализировать контрольным органам о несостоятельности компании по выполнению своих обязательств по теплоснабжению потребителей и необходимости принятия соответствующих организационных мер.

В идеале тарифы на тепловую и электрическую энергию ТЭЦ должны формироваться на компромиссной основе и рассчитываться с учетом интересов как производителей, так и потребителей, используя маркетинговый принцип, основанный на изучении потребностей рынков и складывающихся на них ценах на тепло- и электроэнергию. Рынок электроэнергии и тепла должен строиться так, чтобы он был эффективным для всех его участников - и производителей, и потребителей энергии.

С целью согласования рынков электрической и тепловой энергии необходимо предусмотреть возможность выхода всех энергоисточников как на оптовый, так и на розничный рынки, 
и заключения прямых договоров потребителей с производителями энергии и сетевыми компаниями - для исключения посредников и появления конкуренции как между поставщиками энергии, так и на стороне потребителей. Это будет способствовать если не снижению, то, как минимум, сдерживанию роста тарифов.

Эффективным направлением с точки зрения сокращения издержек и расширения функциональных возможностей систем энергоснабжения представляется интеграция розничных рынков электроэнергии и тепловых рынков. При моделировании работы интегрированного рынка тепловой и электрической энергии целесообразно рассматривать его в границах региональных территорий (в рамках розничных рынков или агломераций), а его эффективность оценивать одним общим критерием - суммарной выручкой от продажи электрической и тепловой энергии. Такие критерии оценки эффективности предлагаются зарубежными и отечественными исследователями [Молодюк, 2017; Стенников, Жарков, 2017].

Из других назревших мер тарифной политики можно назвать следующие:

1) отказ от единой формы организации теплоснабжения и системы тарифообразования в регионах России - это представляется нецелесообразным из-за огромной территориальной разобщенности, различных климатических условий, исторически сложившихся организационных, технологических и др. различий систем теплоснабжения и экономики регионов. Необходимо формировать тарифное меню, обеспечивающее учет индивидуальных особенностей энергетики и экономики регионов России и возможных последствий для всех участников рынка;

2) целесообразность введения системы долгосрочных тарифов на естественно-монопольный вид деятельности (передача тепловой энергии), которые должны сохраняться неизменными в течение длительного периода, независимо от снижения затрат в результате модернизации производства и повышения операционной эффективности. Это будет стимулировать сокращение издержек и позволит окупить инвестиционные вложения.

\section{Трансформация теплоснабжающих систем}

За прошедший период своего развития с конца XIX века по настоящее время системы теплоснабжения в мире прошли 
путь технологической трансформации четырех поколений. Первые из них были созданы в Локпорте (Lockport), Нью-Йорк, США [Diamont, Kut, 1980] и представляли собой паровые системы с прокладкой паропроводов в железобетонных каналах с паровыми ловушками и компенсаторами. Дорогие, небезопасные, малоэффективные, они имели ограниченные возможности регулирования тепловой нагрузки, небольшую дальность транспорта и были подвержены высокой коррозионной активности и температурным деформациям. В России впервые паровые системы появились в 1903 г. и предназначались для отопления корпусов Петербургской детской больницы [Богданов, 2009].

Замена парового теплоносителя на воду повышенной температуры и давления привела к созданию систем теплоснабжения второго поколения, расцвет которых пришелся на 1930-1970 гг. Они имели двухтрубную конструкцию тепловых сетей (подающий и обратный трубопровод, которые прокладывались в бетонных каналах) и были оснащены громоздкой запорно-регулирующей арматурой, большими трубчатыми теплообменниками. Система контроля и учета не предусматривалась. Эти технологии применяются в России до сих пор.

Технология третьего поколения, получившая название «скандинавской», сформировалась в 1970-х гг. Теплоносителем в этих системах по-прежнему остается вода, но ее температура в подающей магистрали не превышает $100{ }^{\circ} \mathrm{C}$, и давление понижено. При этом используются изолированные теплопроводы с бесканальной прокладкой, широко применяются малогабаритные пластинчатые теплообменники, компактные автоматизированные тепловые пункты. За рубежом эти технологии распространены повсеместно, в России только начинают применяться. ФЗ № 190 «О теплоснабжении» регламентирует переход к 2022 г. лишь на закрытую систему горячего водоснабжения, сохраняя зависимую схему отопления без его отделения от тепловых сетей с помощью теплообменника.

Технологии четвертого поколения значительно развивают достигнутые технические уровни своих предшественников и предусматривают дальнейшее понижение температуры и давления теплоносителя, повышение экономической и энергетической эффективности, интеллектуализацию управления и, что очень важно, вовлечение в теплоснабжение нетрадиционных 
и возобновляемых источников энергии, что позиционируется как важный фактор снижения негативного воздействия на окружающую среду и климат. В перспективе такие системы должны быть интегрированы в единую энергетическую метасистему с включением в нее тепло-, электро-, газо-, холодоснабжающих и других инфраструктурных систем [Lund, 2018].

Параллельно предполагается переход к высокоэффективным энергосберегающим системам теплопотребления зданий, новым моделям ценообразования и мотивации, организационным преобразованиям, изменяющим бизнес процессы и принципы взаимодействия участников рынка.

Передовые европейские страны сегодня находятся на этапе перехода от третьего к четвертому поколению энергосистем, Россия в этом отношении отстает от них на целое поколение. В ближайшей перспективе отечественному теплоснабжению предстоит осуществить переход от одноконтурной системы теплоснабжения $^{13}$ к двух ${ }^{14}$-, трехконтурной ${ }^{15}$ системе, включающей индивидуальные автоматизированные тепловые пункты и теплообменники. Это сделает возможным изменить технологию функционирования систем и перейти к регулированию теплоснабжения потребителей в реальном режиме времени, значительно повысив его эффективность.

Существенное повышение эффективности теплоснабжения, причем без значительных капиталовложений, может быть достигнуто в результате организационной трансформации отрасли.

Прежде всего, необходимо наделить Министерство энергетики ответственностью за успешное комплексное развитие сектора, сосредоточив в его руках координирующие и регулирующие функции в рамках государственной энергетической политики. Это позволит устранить имеющуюся разобщенность (организационную, техническую, финансовую и т.п.) теплоснабжения

\footnotetext{
${ }^{13}$ Одноконтурная система теплоснабжения - та, в которой отбор теплоносителя, произведенного на источнике тепла, осуществляется непосредственно из тепловой сети.

${ }^{14}$ Двухконтурная система теплоснабжения обеспечивает гидравлическую изоляцию теплопотребляющих установок от источников тепла и тепловых сетей. Такие системы применяются, как правило, в небольших системах теплоснабжения.

15 Трехконтурные системы теплоснабжения состоят из трех гидравлически независимых контуров-источник тепла, тепловые сети, системы теплопотребления отделенных друг от друга посредством теплообменников. Такие системы должны применяться в крупных теплоснабжающих системах со сложным рельефом местности.
} 
между множеством министерств и ведомств и сконцентрировать управление его развитием и ответственность в одной структуре. При этом должна быть создана иерархически упорядоченная система государственного, муниципального и корпоративного управления теплоснабжением с соответствующим разделением функций и ответственности.

В настоящее время появилось множество собственников. Взаимоотношения между ними муниципальными и государственными структурами не регламентированы. Вся ответственность за теплоснабжение возложена на муниципальные органы власти. Все другие структуры государственной власти устраняются от решения назревших проблем, например в части формирования и проведения государственной технической политики, механизмов ее реализации и т.д.

В целях стимулирования развития теплофикации необходимо обеспечить согласованное развитие двух рынков - тепловой и электрической энергии. Для этого, на наш взгляд, следует сформировать двухуровневую иерархически построенную структуру: оптовый (балансирующий) электрический рынок (на который на конкурентной основе будут поставляться только избытки электроэнергии/мощности) и полноценные локальные электрические и тепловые розничные рынки, находящиеся под пристальным вниманием регулятора. При этом в розничный сегмент должны быть выведены все электростанции и теплоисточники (прежде всего ТЭЦ и когенерационные установки, независимо от их мощности и принадлежности), а также тепловые и распределительные электрические сети. Производство тепловой энергии на всех теплоисточниках и ее поставка в тепловые сети должны осуществляться на конкурентных условиях.

Это в перспективе хорошо вписывается в организационную структуру управления, представленную единой энергоснабжающей организацией ${ }^{16}$. Такая схема уже начинает внедряться в европейских странах, когда городские системы электро-, тепло-, газо-, водоснабжения и водоотведения интегрируются

\footnotetext{
${ }^{16}$ Единая энергоснабжающая организация обеспечивает недискриминационный доступ к сетевому комплексу независимых производителей энергии и потребителей и объединять на территории всю естественно-монопольную сферу деятельности, направленную на функционирование и развитие сетей.
} 
в единую энергетическую инфраструктуру с сетецентрическим управлением [Schmidt et al., 2014]. Интеграция городской инженерной инфраструктуры становится все более актуальной в связи с развитием процессов цифровизации, интеллектуализации и информатизации инженерных систем.

Реализация вышеперечисленных предложений позволит преодолеть сложившиеся негативные тенденции и достигнуть положительных результатов. Целевые ориентиры осуществления такого преобразования теплоснабжения и индикаторы их выполнения приведены в таблице 2 .

\section{Таблица 2. Приоритеты и индикаторы эффективности систем теплоснабжении}

\begin{tabular}{|c|c|}
\hline Важнейшая целевая установка & $\begin{array}{c}\text { Индикатор эффективности } \\
\text { теплоснабжения }\end{array}$ \\
\hline $\begin{array}{l}\text { Повышение уровня комфорта в жилых, общест- } \\
\text { венных и производственных помещениях путем } \\
\text { расширения комплекса предоставляемых услуг } \\
\text { по теплоснабжению (отопление, хладоснабже- } \\
\text { ние, вентиляция, кондиционирование, горячее } \\
\text { водоснабжение) }\end{array}$ & $\begin{array}{l}\text { Последовательное снижение издержек напоставку } \\
\text { тепловой энергии потребителям не менее чем } \\
\text { на } 15-20 \%\end{array}$ \\
\hline $\begin{array}{l}\text { Обеспечение экономической доступности услуг } \\
\text { по теплоснабжению для потребителей }\end{array}$ & $\begin{array}{l}\text { Повышение отпуска тепла от ТЭЦ в } 1,5-2,0 \text { раза } \\
\text { путем возврата бывших и привлечения новых } \\
\text { потребителей }\end{array}$ \\
\hline $\begin{array}{l}\text { Кардинальное повышение технического уровня } \\
\text { систем на основе инновационных, энергоэффек- } \\
\text { тивных технологий и оборудования }\end{array}$ & $\begin{array}{l}\text { Увеличениедолиэлектроэнергии, вырабатываемой } \\
\text { на тепловом потреблении, с 28\% до 45-50\% }\end{array}$ \\
\hline $\begin{array}{l}\text { Значительное повышение энергетической эффек- } \\
\text { тивности теплоснабжения, сокращение непроиз- } \\
\text { водительных потерь тепла и расходов топлива }\end{array}$ & $\begin{array}{l}\text { Рост доли тепла, вырабатываемого в теплофика- } \\
\text { ционном режиме, с } 48 \% \text { до } 65 \%\end{array}$ \\
\hline $\begin{array}{l}\text { Обеспечение управляемости, надежности и эко- } \\
\text { номичности теплоснабжения }\end{array}$ & $\begin{array}{l}\text { Повышениекоэффициента использованияустанов- } \\
\text { ленной мощности ТЭЦ с } 67 \% \text { до 80\% (проектного } \\
\text { показателя) }\end{array}$ \\
\hline $\begin{array}{l}\text { Снижение удельных выбросов в атмосферу, воду, } \\
\text { сокращение негативного воздействия на окружа- } \\
\text { ющую среду }\end{array}$ & $\begin{array}{l}\text { Увеличение коэффициента полезного использо- } \\
\text { вания тепла топлива с } 52 \% \text { до 90\%, как в евро- } \\
\text { пейских странах }\end{array}$ \\
\hline \multirow{2}{*}{$\begin{array}{l}\text { Критерии успешности реформ - положительная } \\
\text { динамика показателей: } \\
\text { стоимость тепловой энергии должна падать; } \\
\text { доступность тепловой энергии должна расти; } \\
\text { надежность и качество теплоснабжения должны } \\
\text { повышаться }\end{array}$} & $\begin{array}{l}\text { Сокращение числа котельных, прежде всего, } \\
\text { работающих на природном газе, в 1,7-2 раза }\end{array}$ \\
\hline & $\begin{array}{l}\text { Снижение денежных расходов, в первую очередь, } \\
\text { населения и бюджетов разных уровней на оплату } \\
\text { тепловой энергии в } 1,5 \text { раза }\end{array}$ \\
\hline
\end{tabular}




\section{Заключение}

В процессе проведенных реформ в энергетике теплоснабжение России во многом утратило достижения советского периода. Это подтверждается многими негативными тенденциями, которые проявляются в снижении уровня теплофикации, росте числа мелких менее экономичных котельных, сокращении протяжённости тепловых сетей централизованных систем, уменьшении отпуска отработанного тепла, увеличении непроизводительных потерь тепловой энергии по всей технологической цепочке и др.

Предложенные в Ф3 №190 «О теплоснабжении» меры по организации новой модели теплового рынка «ЕТО+АК», призванные стимулировать приток инвестиций, не решают назревшие проблемы, а еще более их обостряют.

Важнейшей, так и не нашедшей своего решения ни в одном из законодательных актов, является проблема согласования рынков тепловой и электрической энергии.

Для изменения сложившейся ситуации в теплоснабжении необходимо законодательно изменить модель организации теплоснабжения с организацией ЕТО лишь для естественномонопольной сферы деятельности - передачи и распределения тепловой энергии по тепловым сетям. Цена альтернативной котельной должна быть только предельным индикативным уровнем.

Для согласования рынков тепловой и электрической энергии необходимо обеспечить интеграцию розничных секторов этих рынков с прямым выходом на них потребителей, исключив всех посредников.

Теплоснабжение - важнейшая сфера услуг, оказываемых широкому кругу потребителей, это отрасль, которая определяет благосостояние нашего общества, социальную стабильность и конкурентоспособность экономики страны. Улучшение этих показателей - государственная задача, успешному решению которой должны способствовать эффективные реформы, проводимые в теплоснабжающей отрасли энергетики.

\section{Литература}

Богданов А.Б. История взлетов и падений теплофикации России// Энергосбережение.2009. № 3. С. 42-47.

Богданов А.Б. Котельнизация России - беда национального масштаба. Комбинированное потребление энергии от ТЭЦ - фундамент энергосбережения // Энергорынок. 2008. № 1(50). С. 28-34. 
Гашо Е.Г. Отрасль теплоснабжения сегодня рождается заново // Энергосбережение. 2013. № 7. С. 28-31.

Гашо Е.Г., Пузаков В.С., Степанова М.В. Резервы и приоритеты теплоэнергоснабжения российских городов в современных условиях. М.: ИНП РАН, 2015. $97 \mathrm{c}$.

Гуторов В.Ф., Байбаков С.А. 100 лет развития теплофикации в России// Энергосбережение. 2003. № 5. С. 32-35.

Макаров А.А., Воропай Н.И., Стенников В.А. Системные исследования в энергетике: методология и результаты. М.: ИНЭИ РАН, 2018, 309 с.

Молодюк В. В. Метод расчета тарифов ТЭЦ на региональном рынке электрической и тепловой энергии при условии достижения максимальной балансовой прибыли всех участников рынка// Энергосовет. 2017. № 48. С. 29-36.

Некрасов А.С., Воронина С.А., Семикашев В.В. Проблемы обеспечения населения России тепловой энергией // Проблемы прогнозирования. 2012. № 2. С. 24-33.

Пеньковский A. B. Методы оптимального распределения нагрузки между источниками тепла в задачах развития теплоснабжающих систем в условиях несовпадающих интересов. Автореф. канд. дисс. Иркутск, 2017.

Попьрин Л.С., Светлов К.С., Беляева Г.М и др. Исследования систем теплоснабжения. М.: Наука, 1989, 215 с.

Сергеев B. Состояние теплоэнергетики в России: проблемы и перспективы// Промышленные страницы Сибири. 2018. № 9 (132).С. 54-55.

Стенников В. А., Жарков С. В. Эффективные направления технической политики в энергоснабжении// Известия Российской академии наук. Энергетика. 2017. № 5. C. 19-31.

Стенников В., Славин Г. Концепция «альтернативной котельной»-разрушитель теплофикации // ЭнергоРынок. 2014. № 2. С. 22-29.

Стенников В.А., Пеньковский А. В. Теплоснабжение потребителей в условиях рынка: современное состояние и тенденции развития// ЭКО. 2019. № 3. C. $8-20$.

Хрилев Л. С. Теплофикационные системы. М.: Энергоатомиздат, 1988. 272 с.

Henrik Lund, Poul Alberg Østergaard, Miguel Chang, Sven Werner, Svend Svendsen, Peter Sorknces, Jan Eric Thorsen, Frede Hvelplund, Bent Ole Gram Mortensen, Brian Vad Mathiesen, Carsten Bojesen, Neven Duic, Xiliang Zhang, Bernd Möller. The status of 4-th generation district heating: Research and results// Energy. 2018. № 164. Pp.147-159.

Diamont R. M. E., Kut D. District Heating and Cooling for Energy Conservation, The Architect Press, London, 1980,350 p.

Schmidt R., Fevrier N., Dumas Ph. Key to Innovation Integrated Solution^ Smart Thermal Grids // Smart Cities Stakeholder Platform, Brussels, 2013, 87 p.

Статья поступила 13.06.2019.

Для цитирования: Стенников В. А., Пеньковский А. В. Проблемы российского теплоснабжения и пути их решения// ЭКО. 2019. № 9. С. 48-69. DOI: 10.30680/ECO0131-7652-2019-9-48-69. 


\section{Summary}

Stennikov, V.A., Doct. Sci. (Tech.), Penkovskii, A. V., Cand. Sci. (Tech.), Melentiev Energy Systems Institute, SB RAS, Irkutsk

\section{Problems of the Russian Heat Supply and Ways of Solvung them}

Abstract. The heat supply in Russia, two thirds of which is located in harsh climatic conditions, is the most important social sector of the economy, which largely determines the country's energy security. Many problems have accumulated over the past period heat supply reforms. This is primarily due to the lack of mechanisms to manage the way they function and develop. The target model of the heat market adopted by the Government of the Russian Federation does not eliminate these problems, and aggravates the situation even more. To change the current situation, it is necessary to carry out organizational transformation of retail electricity and heat markets, turn around relations between suppliers and consumers of heat energy, introduce a tariff-based system based on marketing principles and focus on best technologies achieved. This will ensure technological transformation and improve the reliability and availability of heat supply. Implementation of these activities will require development and adoption of an appropriate set of legislative and regulatory documents.

Keywords: heat supply; target model of the heating market; alternative boiler; reform; development directions; integrated energy markets

\section{Reference}

Bogdanov, A.B. (2009). The history of the ups and downs of Russia's heating. Energosberezhenie. Energy saving. No. 3. Pp. 42-47. (In Russ.).

Bogdanov, A.B. (2008). Large-scale construction of boilers in Russia is a national scale problem. Combined energy consumption from $\mathrm{CHP}$ - the foundation of energy saving. Energorynok. Energy market. No. 1(50). Pp. 24-34. (In Russ.).

Diamont, R. M. E., Kut, D. (1980). District Heating and Cooling for Energy Conservation, The Architect Press, London, 350 p.

Gasho, E.G. (2013). The heat supply industry is reborn today. Energosberezhenie. Energy saving. No. 7. Pp. 28-31. (In Russ.).

Gasho, E.G., Puzakov, V.S., Stepanova, M.V. (2015). Reserves and priorities of heat and power supply of Russian cities in modern conditions. Moscow, IEF RAS. 97 p. (In Russ.).

Gutorov, V.F., Bajbakov, S.A. (2003). 100 years of development of district heating in Russia. Energosberezhenie. Energy saving. No. 5. Pp. 32-35. (In Russ.).

Henrik, Lund, Poul, Alberg Østergaard, Miguel, Chang, Sven, Werner, Svend, Svendsen, Peter, Sorknæs, Jan Eric, Thorsen, Frede, Hvelplund, Bent Ole Gram, Mortensen, Brian Vad, Mathiesen, Carsten, Bojesen, Neven, Duic, Xiliang, Zhang, Bernd, Möller. (2018). The status of 4-th generation district heating: Research and results. Energy. No. 164. Pp.147-159.

Hrilev, L.S. (1988). District heating system. Moscow, Energoatomizdat. 272 p. (In Russ.).

Molodyuk, V.V. (2017). The method of calculating tariffs CHP in the regional market of electric and heat energy, subject to the achievement of the maximum balance sheet profit of all market participants. Energy Council. Energosovet. No.48. Pp.29-36. (In Russ.). 
Makarov, A.A., Voropai, N.I., Stennikov, V.A. (2018). Systems research in the energy: methodology and results. Moscow, ERI RAS. 309 p. (In Russ.).

Nekrasov, A.S., Voronina, S.A., Semikashev, V.V. (2012). Problems of providing the population of Russia with thermal energy. Problems of forecasting. Problemi prognozirovania. No.2. Pp. 24-33. (In Russ.).

Penkovskii, A.V.(2017). Methods of optimal load distribution among heat sources in the problems of district heating systems development in the conditions of different interests. Diss. kand. tehn. nauk. Irkutsk. 149 p. (In Russ.).

Popyrin, L.S., Svetlov, K.S., Belyaeva, G.M. et al. (1989). District heating system investigation. Moscow, Nauka Publ. 215 p. (In Russ.).

Sergeev, V. (2018). State of heat power engineering in Russia: problems and prospects. Industrial pages of Siberia. Promyshlennye stranicy Sibiri. No.9 (132). Pp.54-55. (In Russ.).

Schmidt, R., Fevrier, N., Dumas, Ph. (2013). Key to Innovation Integrated Solution: Smart Thermal Grids. Brussels: Smart Cities Stakeholder Platform.87 p.

Stennikov, V.A., Zharkov, S.V. (2017). Effective lines of technical policy on energy supply. Proceedings of the russian academy of sciences. Power engineering. Izvestiya rossijskoj akademii nauk. Energetika. No.5. Pp.19-31. (In Russ.).

Stennikov, V., Slavin, G. (2014). The concept of "Alternative boiler" - the destroyer of district heating systems. Energy market. Energorynok. No. 2. Pp. 22-29. (In Russ.).

Stennikov, V.A., Penkovskii, A.V. (2019). Heat supply of consumers under market conditions: current status and development trends. ECO. No. 3. Pp. 8-20. (In Russ.).

For citation: Stennikov, V.A., Penkovskii, A.V. (2019). Problems of the Russian Heat Supply and Ways of Solvung them. ECO. No. 9. Pp. 48-69. (In Russ.). DOI: 10.30680/ECO0131-7652-2019-9-48-69. 